\title{
Effect of Biotic Factors on Growth and Survival of the Oriental River Prawn Macrobrachium nipponense (De Haan) in Warm-Water Aquaculture
}

\author{
V. F. Kulesh \\ Belarusian State Pedagogical University, \\ ul. Sovetskaya 18, Minsk, 220809 Belarus; \\ e-mail:victor_kulesh@tut.by \\ Received June 12, 2007
}

\begin{abstract}
Biotic factors such as intraspecific competition, stocking density, and parameters of feeding have been compared with respect to their effect on the growth and survival of monosex and mixed populations of the Oriental river prawn Macrobrachium nipponense (De Haan) in warm-water aquaculture. The results suggest that biotic factors - in the present case, social interactions and, to some extent, the efficiency of food assimilation - may be more effective than genetic factors in controlling differences in the size composition of the population.
\end{abstract}

Key words: Oriental river prawn, growth, survival, stocking density, intraspecific competition, females, males. DOI: $10.1134 / \mathrm{S} 1067413609060058$

In the world's shellfishery and aquaculture, farming of the Oriental river prawn, Macrobrachium nipponense (de Haan), occupies the second place after that of the giant freshwater prawn $M$. rosenbergii (De Man) and has been rapidly growing during the past five years. The main producer is China, where marketable prawn production between 1999 and 2001 increased from 15000 to $120000 \mathrm{t}$, with half of this amount being aquacultured in farms (New, 2005).

As shown in long-term studies (Khmeleva et al., 1988, 1997; Kulesh, 2006) the Oriental river prawn may be successfully cage-cultivated together with fish in cooling ponds of thermoelectric power plants, and its yield in earthen fishponds at the end of the growing season (early October) may reach 50-50 ind. $/ \mathrm{m}^{2}$ (Alekhnovich and Kulesh, 2002). An advantage of this species is that it spawns in fresh waters and grows to a considerable body size, which reaches $86 \mathrm{~mm}$ in males and $75 \mathrm{~mm}$ in females within the natural species range (New, 2005) and 88 and $80 \mathrm{~mm}$, respectively, under conditions of cultivation in cooling ponds of the thermoelectric plant.

To understand mechanisms regulating population growth, special attention should be paid to intraspecific competition, which leads to a density-dependent increase in mortality or decrease in birth rate. In studies on this phenomenon, it is generally accepted that all competing individuals are equivalent to each other, but in fact this is far from being so.

In freshwater prawns, especially in the giant freshwater prawn, males and females show two different growth strategies, and the size distribution of individuals in the population depends on the presence of three mature male morphotypes: small males (SM), orange claw males (OC), and large blue claw (BC). These morphotypes differ not only in their morphology but also in physiology and behavior. Small males and blue claw males are reproductively active but grow slowly, while orange claw males are at the intermediate stage of rapid growth, when almost all energy is expended for somatic growth (RaÕanan and Sagi, 1985; Kuris et al., 1987; Karplus et al., 2000). A wide range of size variation is unfavorable for the final yield of prawns.

Thus, individual growth heterogeneity is the main obstacle to improving the economic yield of prawn culture. To overcome this obstacle, it is important to gain an insight into biotic factors regulating growth in the population, including the effects of population density and social interactions (Karplus, 2005).

Freshwater prawns have not been studied in this respect, except for $M$. rosenbergii. The purpose of this study was to analyze the effects of stocking density and intraspecific competition in M. nipponense aquaculture on the basis of data on the growth and survival rates and feeding of prawns in experimental monosex and mixed populations.

\section{MATERIAL AND METHODS}

Studies of $M$. nipponense prawns were performed in the incubation unit of the Selets fish farm, Belozer- 

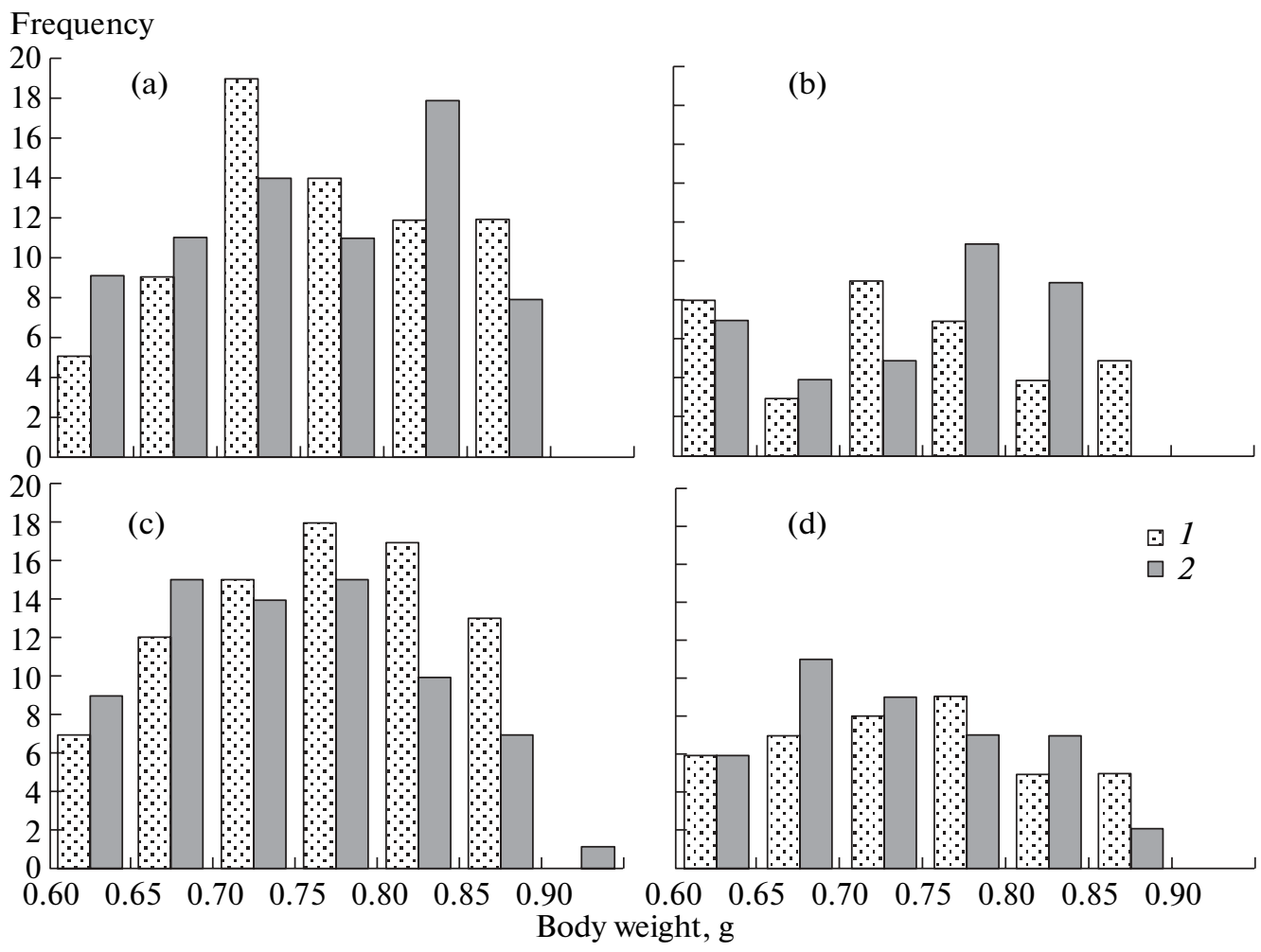

Fig. 1. Range of the initial body weight of ( 1 ) female and (2) male Oriental river prawns in (a, c) monosex and (b, d) mixed populations with initial stocking densities of $(\mathrm{a}, \mathrm{b}) 40$ and $(\mathrm{c}, \mathrm{d}) 80$ ind. $/ \mathrm{m}^{2}$.

skoe branch (Brest oblast, Belarus). Juvenile prawns were caught in the warm-water spillway of the Bereza State District Power Plant (BPP). Experiments on their growth and survival were made in six to seven replications. The initial individual body weight ranged from 0.600 to $0.900 \mathrm{~g}$ (Fig. 1). Each empirical point in growth curves (Fig. 2) is an average of 3-12 measure-

Table 1. Hydrochemical parameters in plastic basins with cultured Oriental river prawns

\begin{tabular}{l|c|c}
\hline \multicolumn{1}{c|}{ Parameters } & Minimum & Maximum \\
\hline Temperature, ${ }^{\circ} \mathrm{C}$ & 26.0 & 30.0 \\
Dissolved oxygen, mg/l & 4.5 & 7.9 \\
BOD $_{5}, \mathrm{mg}^{\prime} \mathrm{l} \mathrm{O}_{2}$ & 2.5 & 3.4 \\
$\mathrm{pH}$ & 6.9 & 8.2 \\
Dry residue, mg/l & 350.0 & 393.6 \\
Ignition residue, mg/l & 188.0 & 192.2 \\
Loss on ignition, mg/l & 160.4 & 197.6 \\
Alkalinity, mg-eqiv/l & 3.6 & 3.9 \\
Total hardness, mg-equiv/l & 0.8 & 1.0 \\
Iron, mg/l & 0.04 & 0.07 \\
Nitrate ions, mg/l & 0.1 & 0.3 \\
Nitrite ions, mg/l & 0.01 & 0.02 \\
Phosphate ions, mg/l & 0.1 & 0.4 \\
\hline
\end{tabular}

ments. The experiment was discontinued if the survival of prawns in the course of rearing decreased by more than $50 \%$. Variation coefficients for the initial size composition of experimental populations were similar (9.92-11.42\%), indicating that the biological material was sufficiently uniform.

The prawns were grown in plastic basins $(60 \times 25 \mathrm{~cm}$, surface area $0.150 \mathrm{~m}^{2}$, water depth about $20 \mathrm{~cm}$ ) in heated water discharged from the BPP. The water was continuously aerated and maintained at the temperature optimal for this species $\left(28 \pm 2^{\circ} \mathrm{C}\right)$, with half its volume being replaced every $3-4$ days. Each basin was shaded in half of its area and contained several plastic and ceramic tubes $2-4 \mathrm{~cm}$ in diameter to provide shelter for prawns. Hydrochemical parameters are shown in Table 1.

Competitive relationships were studied in experimental mixed (sex ratio $1: 1$ ) and monosex populations, with the growth and survival of females and males in each population being analyzed separately. The initial stocking densities were 40 and $80 \mathrm{ind} . / \mathrm{m}^{2}$. For the giant freshwater prawn, culturing at a stocking density of up to 30 ind. $/ \mathrm{m}^{2}$ is classified as semi-intensive, and that at a higher density, as intensive (New, 2002). Taking into consideration that the Oriental river prawn is smaller, its culturing at the initial stocking densities of 40 and 80 ind. $/ \mathrm{m}^{2}$ can also be regarded as semi-intensive and intensive, respectively. 


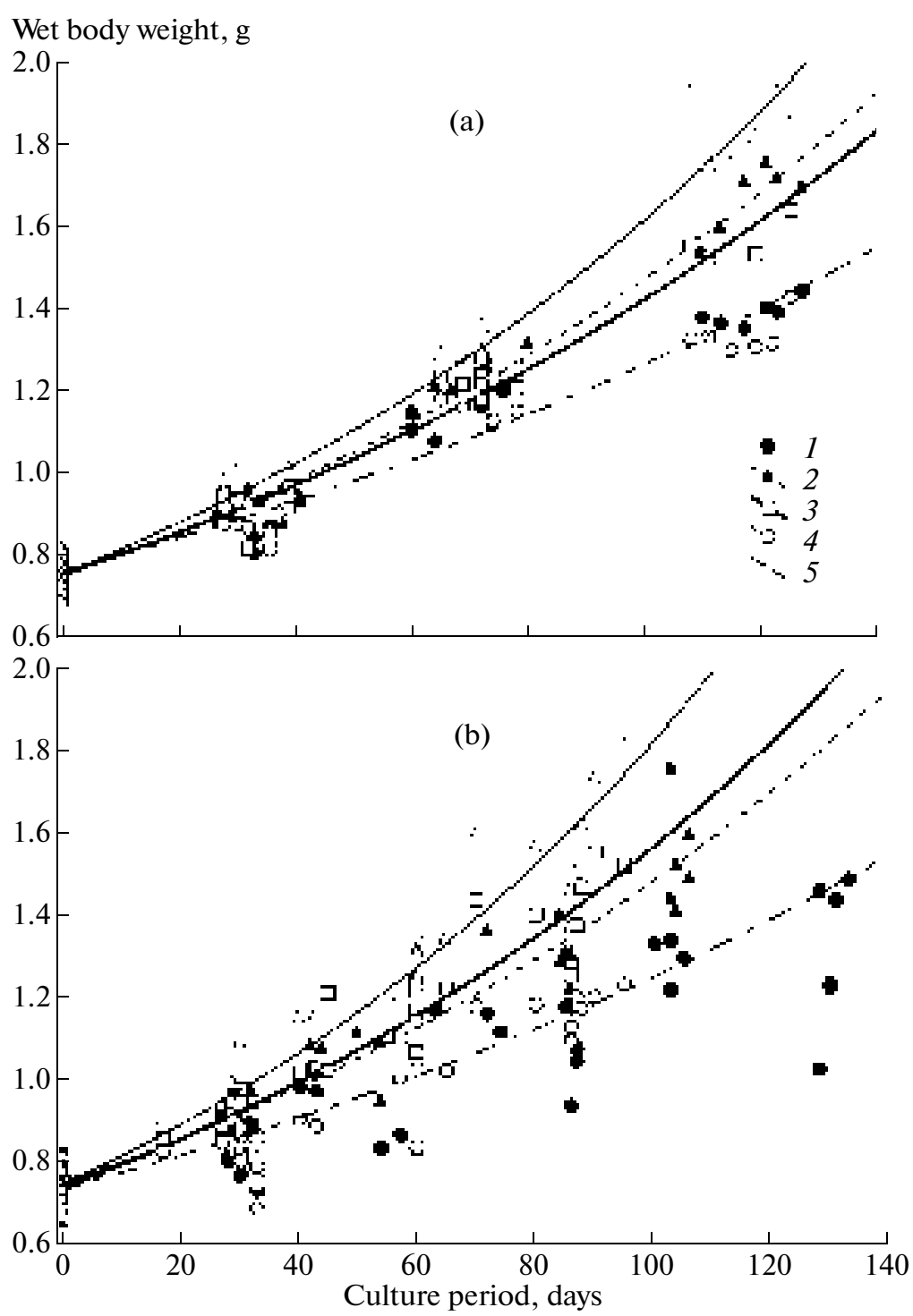

Fig. 2. Growth of female and male Oriental river prawns in monosex and mixed populations with initial stocking densities of (a) 40 and (b) 80 ind. $/ \mathrm{m}^{2}$ : (1) females and (2) males in monosex populations; (3-5) mixed populations: (3) males + females, (4) females, and (5) males.

The prawns were fed ad libitum twice a day with freshly minced fish and chironomid larvae from the BPP cooling pond. Daily food consumption $(r)$ was estimated experimentally, in thee replications, in the beginning of cultivation (days $1-5$ ) and after 50-85 days. Calculations were made by the equation

$$
r=\frac{\left(W_{0}-W_{\tau}\right) 24}{n \tau},
$$

where $W_{0} 0$ and $W_{\tau}$ are the amounts of food at the beginning and at the end of experiment, $\mathrm{g} ; n$ is the number of prawns; and $\tau$ is the period of exposure, h (Sushchenya, 1975).

Variation in growth parameters of prawns was estimated using standard deviation $(\sigma)$ and the coefficient of variation $(\mathrm{CV}, \%)$. Experimental data were processed with the STATISTICA 6.0 program package.

\section{RESULTS}

The growth rate of prawns kept under different conditions in plastic basins is described by an exponential equation of the form

$$
y=a e^{b x},
$$

where $a$ and $b$ are constants, $\mathrm{y}$ is the wet weight of prawns, and $x$ is cultivation period, days.

Table 2 shows parameters of Eqs. (3-12) for the growth rates of prawns in experimental monosex and mixed populations with different initial stocking densities. Growth curves shown in Fig. 2 were calculated 
Table 2. Parameters of equations for body weight $(W, \mathrm{~g})$ as a function of culture period in monosex and mixed Oriental river prawn populations

\begin{tabular}{l|l|c|c|c|c|c|c|c|c}
\hline $\begin{array}{c}\text { Culture } \\
\text { conditions }\end{array}$ & \multicolumn{1}{|c|}{ Sex } & $\begin{array}{c}\text { Culture } \\
\text { period, } \\
\text { days }\end{array}$ & $\begin{array}{c}\text { Body } \\
\text { weight } \\
\text { range, g }\end{array}$ & $a$ & $b$ & $R^{2}$ & $\begin{array}{c}\text { Equation } \\
\text { no. }\end{array}$ \\
\hline $\begin{array}{l}\text { Monosex } \\
\text { population }\end{array}$ & Females & 127 & $0.60-1.90$ & 0.7651 & 0.0051 & 0.957 & $72-56$ & 3 \\
Mixed & Fales & 127 & $0.60-2.38$ & 0.7488 & 0.0068 & 0.981 & $72-48$ & 4 \\
population & Females +males & 125 & $0.61-2.65$ & 0.7516 & 0.0064 & 0.965 & $72-49$ & 5 \\
& Males & 125 & $0.61-1.65$ & 0.7588 & 0.0051 & 0.940 & $36-27$ & 6 \\
Monosex & 125 & $0.61-2.65$ & 0.7531 & 0.0076 & 0.975 & $36-22$ & 7 \\
population & Females & 133 & $0.60-1.74$ & 0.7595 & 0.0044 & 0.765 & $84-47$ & 8 \\
Mixed & Males & 106 & $0.60-2.80$ & 0.7427 & 0.0069 & 0.929 & $84-38$ & 9 \\
population & Females + males & 95 & $0.60-2.26$ & 0.7298 & 0.0076 & 0.906 & $84-41$ & 10 \\
& Females & 95 & $0.60-1.30$ & 0.7288 & 0.0054 & 0.828 & $42-18$ & 11 \\
\hline
\end{tabular}

on the basis of empirical values recorded for these populations.

As follows from Fig. 2a, growth rates in monosex and mixed populations with the initial stocking density of 40 ind. $/ \mathrm{m}^{2}$ remained equal for about 30 days. Between days 27 and 39, significant differences appeared between growth parameters of males and females in monosex populations and between growth parameters of males in mixed populations and those of females in monosex and mixed populations; other differences lacked statistical significance. Similarly significant differences in growth parameters were also observed in the period between days 60 and 80 . The highest growth rate was characteristic of females from the monosex population, and the maximum rate, of males in the mixed population, with their body weights averaging 0.862 and $0.958 \mathrm{~g}$, respectively. Heterogeneity in growth parameters manifested itself still more clearly by the end of the experiment (days 110-127). Significant differences were absent only between prawns of the same sex grown in monosex and mixed populations (Figs. 2a, 3), although the average weight of males from the mixed population $(1.836 \mathrm{~g})$ was greater than of males grown separately. This indicates that, at an initial density of $40 \mathrm{ind} . / \mathrm{m}^{2}$, males inhibit the growth of females. In the monosex population of males, their behavior was more aggressive, and conflict were observed frequently; i.e., competitive relationships manifested themselves more clearly. As a result, male individual body weight in this population averaged only $1.664 \mathrm{~g}$.

In the course of growth, the standard deviation and coefficient of variation increase gradually (Figs. 3, 4). For females, the highest coefficient of variation in body weight $(23.97 \%)$ was recorded noted in the mixed population. This is additional evidence that males inhibit the growth of females and, at lower energy expenditures (fewer aggressive contacts than in the purely male population), their growth rate is higher (Figs, 2a, 4). By days 108-127, the weight of most individuals reached $1.8-2.0 \mathrm{~g}$, while that of females in the mixed population was only $1.2-1.4 \mathrm{~g}$ (Fig. 5b). Thus, after $108-127$ days of culturing at the initial density of 40 ind. $/ \mathrm{m}^{2}$, the average individual body weight reached $1.389 \mathrm{~g}$ in the female population, 1.664 in the male population, and $1.449 \mathrm{~g}$ in the mixed population. The amount of production in the male population was $6.3 \%$ greater than in the mixed population and $16.5 \%$ greater than in the female population.

At the stocking density of 80 ind. $/ \mathrm{m}^{2}$, growth rates in the monosex and mixed population were approximately equal in the initial period, as was the case at 40 ind. $/ \mathrm{m}^{2}$. Between days 27 and 33, however, differences in growth rate were observed not only between females from monosex and mixed populations but also between males from these populations. Moreover, competitive relationships within populations manifested themselves more distinctly. As a result, the range of variation in growth parameters broadened (Figs. 2-4), especially at later growth stages, when the lowest average weight of females was recorded. The range of their weights in all variants was lower than that in males (Fig. 5). The highest coefficient of variation in body weight (27.60-29.86\%) was recorded in the monosex population of males (Fig. 4), being indicative of more active competitive relationships between them. After approximately 100 days, the average individual body weight reached $1.317 \mathrm{~g}$ in the female population, $1.527 \mathrm{~g}$ in the male population, and $1.392 \mathrm{~g}$ in the mixed population; the productivity of the male population exceeded that of the mixed population by $12.8 \%$ and 


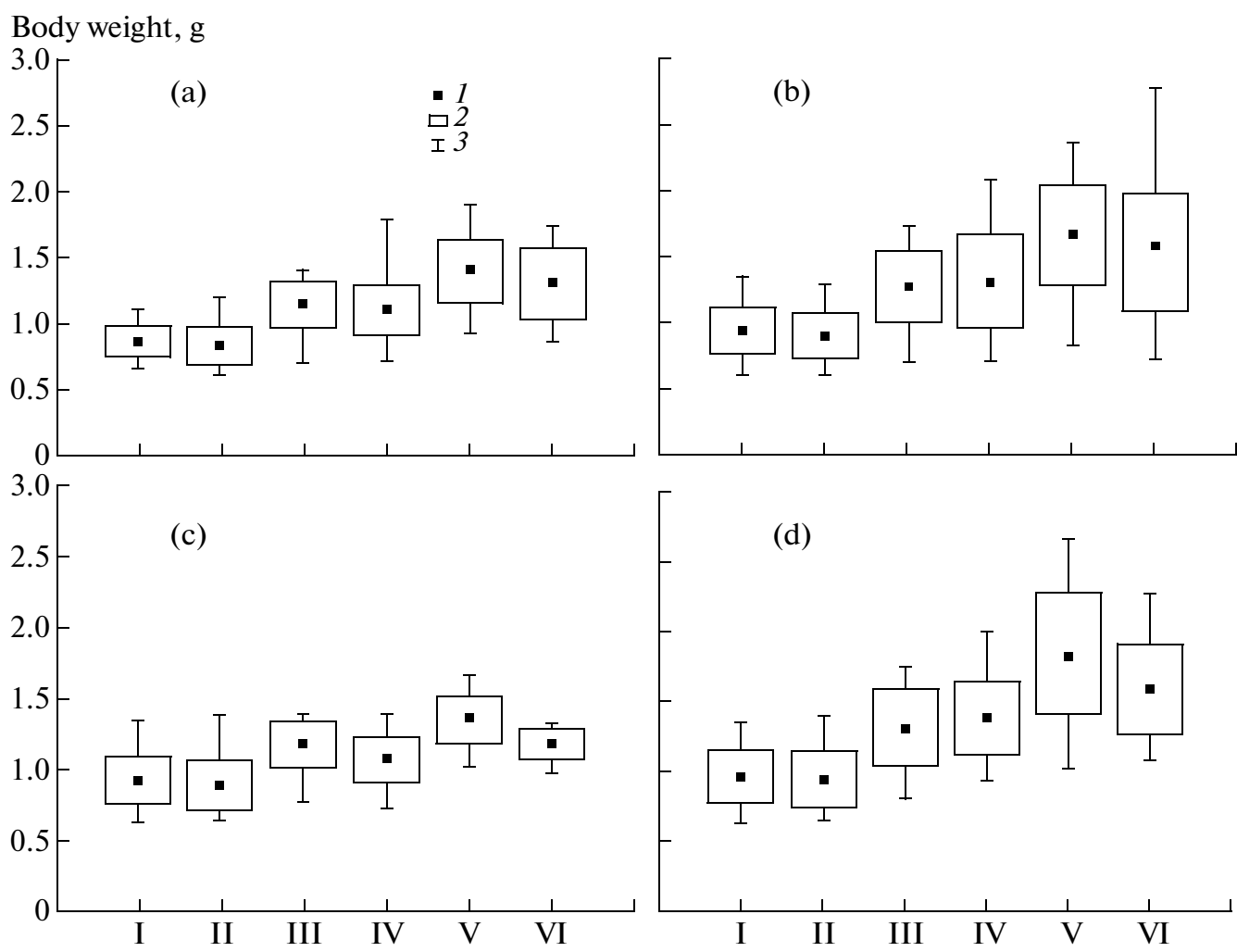

Fig. 3. Average growth parameters of (a, c) female and (b, d) male Oriental river prawns in (a, b) monosex and (c, d) mixed populations with initial stocking densities of (I, III, V) 40 ind. $/ \mathrm{m}^{2}$ and (II, IV, VI) 80 ind./ $\mathrm{m}^{2}$ over culture periods of (I, II) $27-$ 41 days, (III, IV) 57-87 days, and (V, VI) 86-127 days: (1) mean, (2) standard deviation; (3) minimum and maximum values.

of the female population by $17.5 \%$. Due to an abrupt increase in the mortality of females in mixed populations, comparisons of growth and survival rates and variation levels became impossible after 80 days of culturing.

Let us compare the growth of prawns in monosex and mixed populations at the two initial stocking densities. Firstly, the range of variation in body weight in monosex populations, both male and female, at 80 ind. $/ \mathrm{m}^{2}$ was broader than at 40 ind. $/ \mathrm{m}^{2}$ throughout the culture period (Figs. 3, 4). The situation in mixed populations was the same until the final stage, when the growth of females was inhibited by the increased density (Fig. 3c). Secondly, the body weight of prawns throughout the culture period showed a general tendency to be lower in populations with higher stocking density (Fig. 3). In mixed populations, significant differences between growth rates of females and males at different stocking densities were observed at the end of the experiment.

As shown in Fig. 6a, the survival rates of Oriental river prawns in cultures with the initial density of 40 ind. $/ \mathrm{m}^{2}$ began to decrease immediately after the onset of the experiment. The female population was an exception, showing the highest survival rate throughout the culture period. This parameter in females from the mixed population was slightly lower due to compe- tition with males. However, the survival of males in the mixed population was also lower than in the monosex population.

At the initial density of 80 ind. $/ \mathrm{m}^{2}$ (Fig. $6 \mathrm{~b}$ ), the survival rates decreased more abruptly and, at the end of experiment, were significantly lower than at 40 ind. $/ \mathrm{m}^{2}$. In females from the mixed population, this parameter decreased to $43 \%$ by days $80-95$. Due to a high mortality (more than 50\% over 95-106 days), the experiment had to be stopped. Only females in the monosex population survived by days $128-133$.

To estimate what mechanisms account for the level of intraspecific competition, daily food consumption by females and males was compared in monosex and mixed populations with different densities (Table 3). In the initial period, daily food consumption in males was significantly higher than in females only in monosex populations with the initial density of $40 \mathrm{ind} . / \mathrm{m}^{2}$, although this difference was small in absolute values. At the initial density 80 ind. $/ \mathrm{m}^{2}$, food consumption was also somewhat higher in males, but the difference lacked statistical significance. At densities of 33.036.7 and $49.0-55.3$ ind. $/ \mathrm{m}^{2}$, the values of food consumption did not differ significantly between females and males in monosex and mixed populations; however, daily food consumption in females at 55.3 ind. $/ \mathrm{m}^{2}$ was significantly higher than that at $36.7 \mathrm{ind} . / \mathrm{m}^{2}$. 


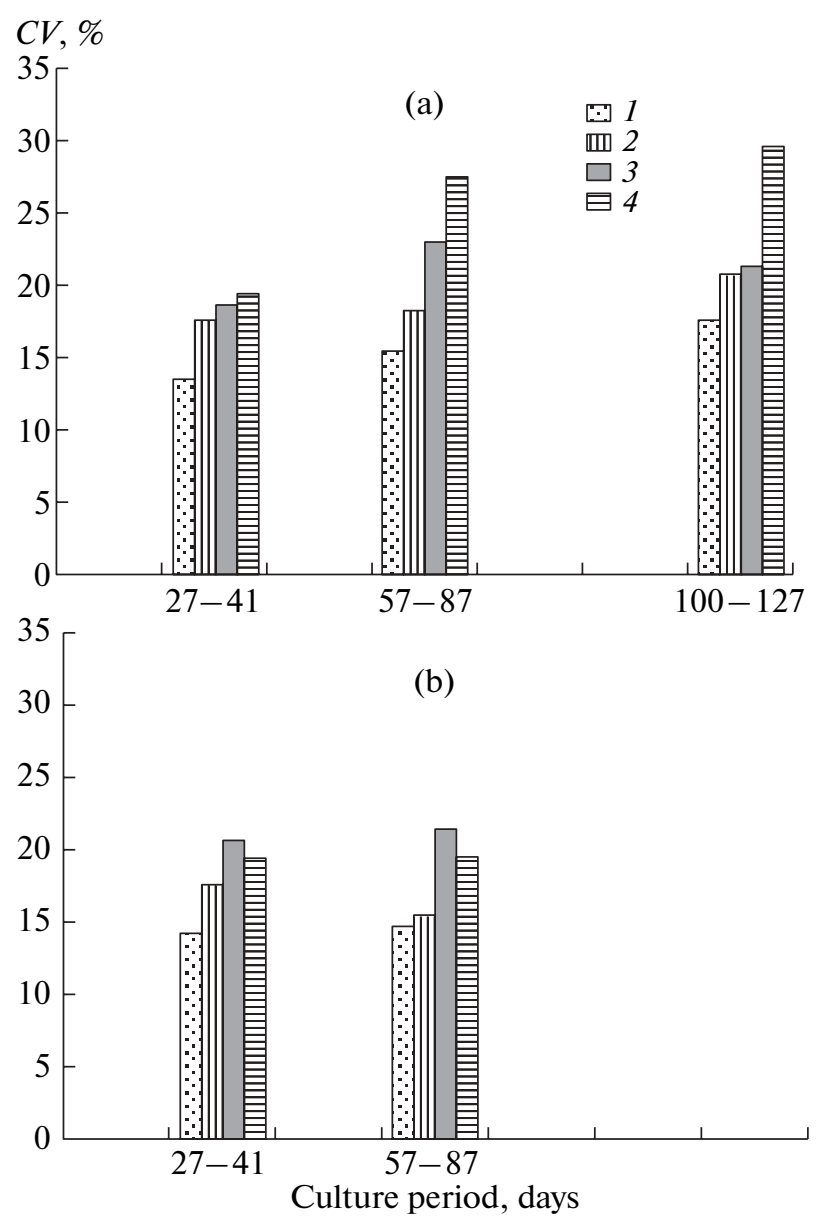

Fig. 4. Coefficients of variation in body weight of $(1,2)$ female and $(3,4)$ male Oriental river prawns in (a) monosex and (b) mixed populations with initial stocking densities of $(1,3) 40$ and $(2,4) 80$ ind. $/ \mathrm{m}^{2}$.

\section{DISCUSSION}

The populations of postlarval freshwater prawns immediately after metamorphosis are relatively homogeneous and have normal size distribution. Differences in average body size among postlarvae of the giant freshwater prawn $M$. rosenbergii aged up to 30 days at stocking densities of 20 to 130 ind. $/ \mathrm{m}^{2}$ lack statistical significance. The values of variance also do not differ; i.e., these postlarvae show identical variation in body size irrespective of density (Alekhnovich and Kulesh, 2003). The result obtained with M. nipponense is similar.

After approximately one month, the population becomes heterogeneous. with respect to individual growth rate. In the giant freshwater prawn M. rosenbergii, the "leading" part of the population is being formed, which consists of larger individuals. Juveniles of this species fall into two categories, rapidly growing, or jumpers, and slowly growing, or laggards. Jumpers grow very rapidly: their body size 60 days after metamorphosis may be 15 times greater than in other mem- bers of the population (Ra'anan and Cohen, 1984; Karplus and Hulata, 1995). The same tendency was found in postlarvae of the Oriental river prawn M. nipponensis (Kulesh and Guiguinyak, 1993).

Growing jumpers develop mainly into large-sized blue claw (BC) and orange claw (OC) morphotypes, while the SM morphotype (small males) is formed of laggards. These three mature morphotypes differing in morphology, physiology, and behavior are not permanent but rather represent stages in the dynamic line of development, and every male can potentially proceed from SM to BC via OC (RaÕanan and Sagi, 1985; Kuris et al., 1987; Karplus et al., 1987, 1991).

The manifestation of individual growth heterogeneity is delayed at a low stocking density. For example, among postlarval $M$. nipponensis prawns aquacultured in rice fields at a density of $2-6$ ind. $/ \mathrm{m}^{2}$, significant differences in growth rate were first only after three months, with males beginning to grow more rapidly than females (Lan et al., 2006).

Karplus (2005) distinguished four different social mechanisms controlling the growth of crustaceans: direct competition for food, inhibition of food requirement, changes in the efficiency of food assimilation, and increasing locomotor activity. In general, it may be concluded that variation in body size depends on two groups of factors, genetic and environmental. However, there is evidence for sexual dimorphism in the heritability of body size: females show a considerable level of genetic control over this character $\left(h^{2}=\right.$ 0.35 ), while in males this index is close to 0 (Malecha et al., 1984).

In the Oriental river prawn, there is no such social structure with subdivision of males into morphotypes as in the giant prawn, but competitive relationships clearly manifest themselves in mixed populations, resulting in the inhibited growth of females. This competition proved to be more acute in case of intensive aquaculture $\left(80\right.$ ind. $\left./ \mathrm{m}^{2}\right)$ : at the end of culturing, the average weight of the male population exceeded that of the mixed population by $12.8 \%$, compared to $6.3 \%$ at $40 \mathrm{ind} . / \mathrm{m}^{2}$, and the excess in weight over the female population was $17.5 \%$, compared to $12.8 \%$ at 40 ind. $/ \mathrm{m}^{2}$. Similar data were obtained for the giant freshwater prawn. For example, the proportion of small-sized males was significantly greater at a stocking density of 60000 ind./ha than at 14000 ind./ha (Lan et al., 2006). After 5 months of culturing in floating cages at stocking densities of $15,30,60$, and 90 ind. $/ \mathrm{m}^{2}$, the proportions of individuals weighing less than $20 \mathrm{~g}$ were $31,48,64$, and $76 \%$, respectively (Cuvin-Aralar et al., 2007).

The results of studies on monosex and mixed populations of $M$. rosenbergii cultured in ponds, cages, and rice fields also show that males grow more rapidly than females and inhibit their growth, while the presence of females has little effect on the growth of males. Commercial yields from purely male populations were $7.8-45.0 \%$ higher than from mixed populations and 

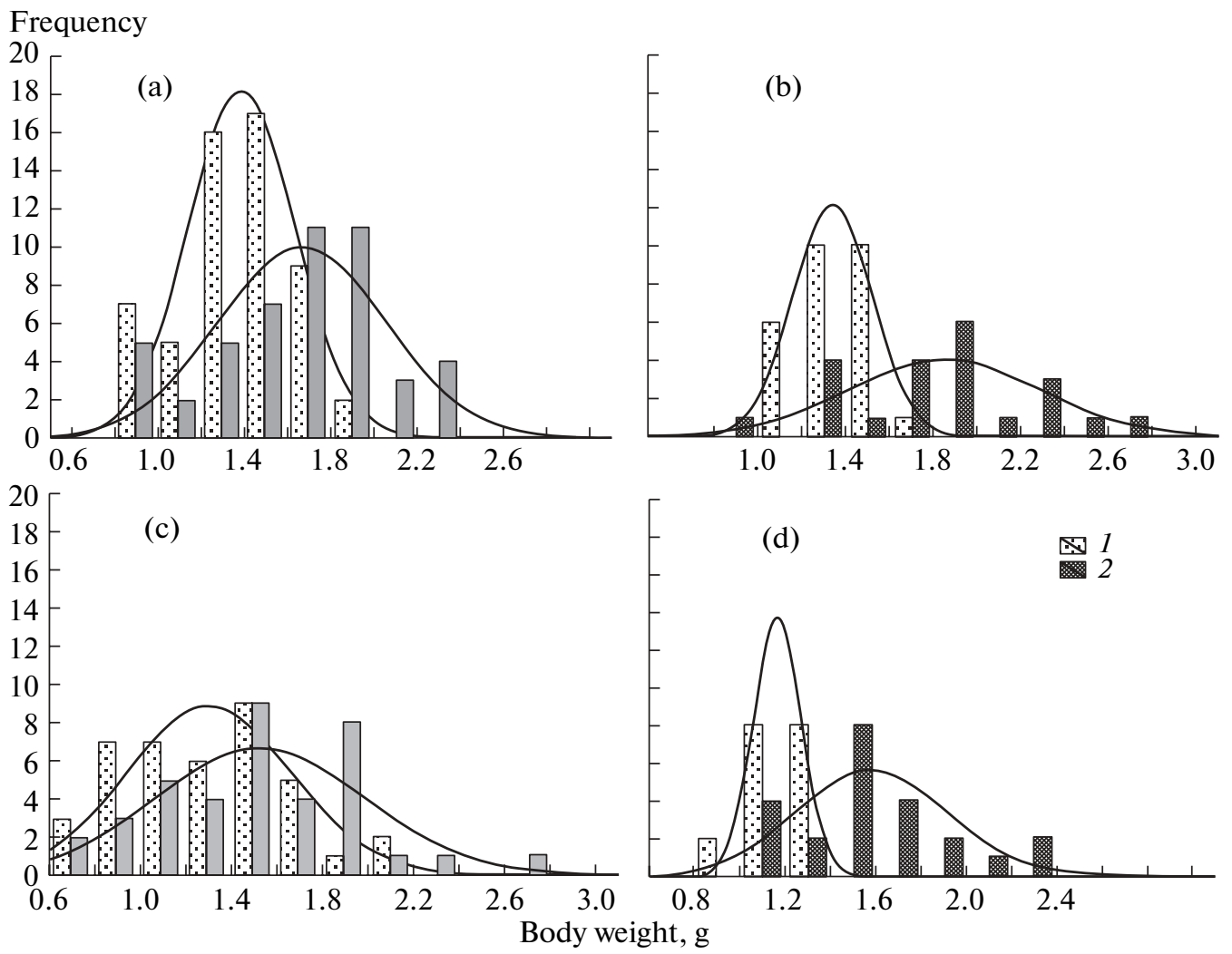

Fig. 5. Definite body weight ranges of (1) female and (2) male Oriental river prawns in (a, c) monosex and (b, d) mixed populations with initial stocking densities of $(a, b) 40$ and $(c, d) 80$ ind. $/ \mathrm{m}^{2}$.

$34.0-47.5 \%$ higher than from female populations, but the body size of females in commercial production was more uniform than that of males (Sagi et al., 1986; Cohen et al., 1988; Lan et al., 2006; Mohanakumaran et al., 2006).

A comparison of these data with our results indicates that the effect of males on females in the giant prawn is stronger. For example, the yield from a monosex female population of this species proved to be more than twice that from females in a mixed population (Sagi et al., 1986).

It has long been shown that the survival of prawns in mixed populations inversely depends on their density: the lower the density, the higher the survival (Alekhnovich and Panyushkin, 1991; Kulesh, 1996; Alekhnovich and Kulesh, 2003; Cuvin-Aralar et al., 2007). In case of semi-intensive M. nipponense culture (40 ind. $/ \mathrm{m}^{2}$ ), the survival rates of females in monosex and mixed populations are significantly higher than those of males. In intensive culture $\left(80 \mathrm{ind} . / \mathrm{m}^{2}\right)$, conversely, life activities of females are inhibited to the extent that their survival rate becomes lower than in males not only in the mixed population but also in the monosex population. Among $M$. rosenbergii prawns grown in ponds at a sufficiently low initial stocking density $\left(9\right.$ ind. $\left./ \mathrm{m}^{2}\right)$, the lowest survival rate was also recorded in the male population: $66.3 \%$, compared to
$75.6 \%$ in the female population and $75.2 \%$ in the mixed population (Cohen et al., 1988). Apparently, competitive relationships between sexes at such a density are not manifested so clearly as in M. nipponense.

Food supply is a major biotic factor determining the level of intraspecific competition. In experiments with giant freshwater prawn receiving a limited amount of food, a positive correlation was revealed between aggressiveness, food consumption, food-storing behavior (after satiation, aggressive prawns collected food and defended it from subordinate individuals), and weight gain (Karplus, 2005). Direct competition for food controlled growth. In case of excess food supply, as in our studies, no correlation between aggressiveness and food consumption was observed. Daily food consumption in equal-sized $M$. nipponense prawns was at the same level and did not decrease in subordinate individuals. This excludes the role of appetite inhibition as a mechanism of growth regulation. Apparently, Karplus (2005) was right in concluding that the main factor in this case is the efficiency of food assimilation. Under conditions of equal access to food, aggressive individuals assimilate it more efficiently and, therefore, grow more rapidly, while subordinate prawns are characterized by a low efficiency of food assimilation. 

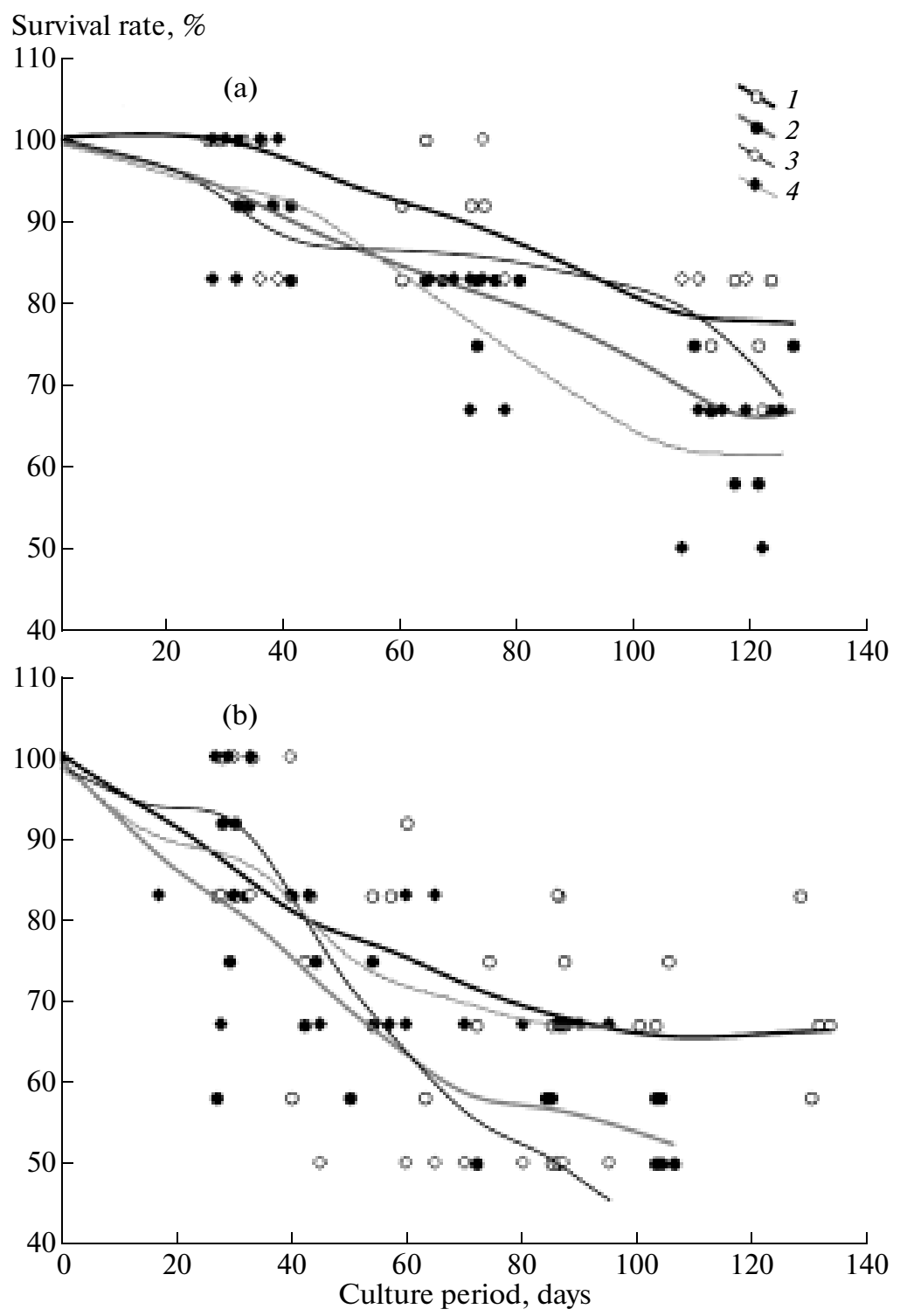

Fig. 6. Survival rates of $(1,3)$ female and $(2,4)$ male Oriental river prawns in $(1,2)$ monosex and $(3,4)$ mixed populations with initial stocking densities of (a) 40 and (b) 80 ind. $/ \mathrm{m}^{2}$.

How can aggressive individuals be identified? As shown by Brown et al. (2003), prawns consuming increased amounts of food and having the highest scaphognathite beat rate in the resting state are the most aggressive. In M. nipponense, this rate is directly related to the rates of heartbeat and oxygen consumption (Giginyak and Kulesh, 1994): the higher the scaphognathite beat rate, the higher the level of metabolism. Therefore, when water temperature remains constant, it is fairly easy to identify the most aggressive and rapidly growing individuals.

Thus, it may be concluded that biotic factors-in the present case, social interactions and, in part, the efficiency of food assimilation-may be more effective than genetic factors in controlling differences in the size composition of freshwater prawn populations.
This conclusion is confirmed by the well-known fact that selective removal of larger individuals from the population stimulates the compensatory growth of remaining smaller individuals (Ra'anan and Cohen, 1984; Karplus, 2005).

The results of this study are indicative of considerable intraspecific competition dependent on density and sex ratio in Oriental river prawn populations. The commercial yield of male populations is higher than that of mixed and female populations, but the size distribution of females is more uniform. Supplementary feeding will not contribute to growth rate as long as the pressure of aggressive individuals remains in the population. This pressure in prawn aquaculture may be alleviated by selective removal of large individuals by trawling, provision of additional substrates increasing 
Table 3. Daily food consumption by female and male Oriental river prawns in monosex and mixed populations with different stocking densities

\begin{tabular}{|c|c|c|c|c|c|c|c|c|c|}
\hline \multirow{2}{*}{$\begin{array}{c}\text { Culture } \\
\text { period, } \\
\text { days }\end{array}$} & \multirow{2}{*}{$\begin{array}{c}\text { Stocking } \\
\text { density, } \\
\text { ind./m² }\end{array}$} & \multirow{2}{*}{ Sex } & \multirow{2}{*}{$\begin{array}{c}\text { Average } \\
\text { body } \\
\text { weight, g }\end{array}$} & \multicolumn{3}{|c|}{$\begin{array}{l}\text { Daily food consumption, } \% \\
\text { of body weight }\end{array}$} & \multirow[t]{2}{*}{$n$} & \multirow{2}{*}{$\sigma$} & \multirow{2}{*}{$C V, \%$} \\
\hline & & & & mean & $\min$. & $\max$ & & & \\
\hline $1-5$ & 40.0 & Females & 0.798 & 20.5 & 17.6 & 23.5 & 18 & 1.761 & 8.9 \\
\hline $1-5$ & 40.0 & Males & 0.752 & 22.5 & 18.4 & 27.2 & 18 & 2.473 & 11.0 \\
\hline $1-5$ & 40.0 & Females + males & 0.753 & 22.7 & 18.7 & 30.3 & 18 & 2.683 & 11.8 \\
\hline $1-5$ & 80.0 & Females & 0.711 & 21.3 & 18.3 & 24.2 & 18 & 1.675 & 7.9 \\
\hline $1-5$ & 80.0 & Males & 0.712 & 23.0 & 18.6 & 30.4 & 18 & 3.455 & 14.7 \\
\hline $1-5$ & 80.0 & Females + males & 0.709 & 22.4 & 18.3 & 27.3 & 18 & 2.551 & 13.4 \\
\hline $60-69$ & 36.7 & Females & 1.110 & 11.5 & 8.5 & 14.5 & 18 & 1.606 & 14.0 \\
\hline $50-60$ & 33.0 & Males & 1.078 & 12.7 & 9.1 & 16.0 & 18 & 2.017 & 15.9 \\
\hline $50-59$ & 33.0 & Females + males & 1.085 & 12.1 & 9.4 & 15.5 & 18 & 1.903 & 15.8 \\
\hline $72-84$ & 55.3 & Females & 1.142 & 12.9 & 10.2 & 15.7 & 18 & 1.575 & 12.1 \\
\hline $50-59$ & 49.0 & Males & 1.108 & 14.0 & 9.4 & 18.3 & 18 & 2.587 & 18.5 \\
\hline $57-65$ & 53.3 & Females + males & 1.111 & 13.3 & 10.5 & 17.3 & 18 & 1.899 & 14.3 \\
\hline
\end{tabular}

Note: $n$ is number of measurements, $\sigma$ is standard deviation, and $C V$ is variation coefficient.

surface area available to prawns, and reduction of the initial stocking density of juveniles in polyculture with fish, as well as by prolonging the period of postlarvae rearing (in winter-spring) in recirculation basins with artificial heating.

\section{REFERENCES}

Alekhnovich, A.V. and Kulesh, V.F., Production Potential of Oriental River Prawn Macrobrachium nipponense (De Haan) in Fish-Farm Ponds of the Cooling Reservoir of the Bereza Electric Power Station (Belarus), Pond Aquaculture in Central and Eastern Europe in the 21st Century (International Worshop, Vodnany, Czech Republic, May 2-4, 2001), Adamek, Z., Ed., European Aquaculture Society Spec. Publ. no. 33, 2002, pp. 102-104.

Alekhnovich, A.V. and Kulesh, V.F., Linear Size Variation in the Giant Freshwater Prawn Macrobrachium rosenbergii (De Man) (Crustacea, Palaemonidae) in the Juvenile Period, Gidrobiol. Zh., 2003, vol. 39, no. 4, pp. 24-33.

Alekhnovich, A.V. and Panyushkin, S.N., Effect of Stocking Density on the Growth and Survival of the Giant Freshwater Prawn in Aquaculture, Dokl. Akad. Nauk SSSR, 1991, vol. 321, no. 3, pp. 626-628.

Brown, J.H., Ross, B., McCauley, S., et al., Resting Metabolic Rate and Social Status in Juvenile Giant Freshwater Prawns, Macrobrachium rosenbergii, Mar. Freshw. Behav. Physiol., 2003, no. 36, pp. 31-40.

Cohen, D., Sagi, A., Ra'anan, Z., and Zohar, G., The Production of Prawn Macrobrachium rosenbergii in Monosex Populations: 3. Yield Characteristics under Intensive Monoculture Conditions in Earthen Ponds, Bamidgeh, 1988, vol. 40, no. 2, pp. 57-63.

Cuvin-Aralar, M.L.A., Aralar, E.V., Laron, M., and Westley, R., Culture of Macrobrachium rosenbergii (De Man 1879) in Experimental Cages in a Freshwater Eutrophic
Lake at Different Stocking Densities, Aquacult. Res., 2007, vol. 38, pp. 288-294.

Guiguinyak, Yu.G. and Kulesh, V.F., Temperature Dependence of Respiration, Heartbeat, and Scaphognathite Beat Rates in Freshwater Prawns, Dokl. Akad. Nauk Belarusi, 1994, vol. 38, no. 5, pp. 88-91.

Karplus, I., Social Control of Growth in Macrobrachium rosenbergii (De Man): A Review and Prospects for Future Research, Aquacult. Res., 2005, vol. 36, pp. 238-254.

Karplus, I., Hulata, G., Wolhlfarth, G., and Halevy, A., The Effect of Size-Grading Juvenile Macrobrachium rosenbergii Prior to Stocking on Their Population Structure and Production in Polyculture: 2. Dividing the Population into Three Fraction, Aquaculture, 1987, vol. 62, pp. 85-95.

Karplus, I., Barki, A., Israel, Y., and Cohen, S., Social Control of Growth in Macrobrachium rosenbergii: 2. The "Leapfrog" Growth Pattern, Aquaculture, 1991, vol. 96, pp. $353-365$.

Karplus, I., Malecha, S., and Sagi, A., The Biology and Management of Size Variation, in Freshwater Prawn Culture, New, M.B. and Walenti, W.C., Eds., New York, 2000, pp. 259-289.

Khmeleva, N.N., Guiguinyak, Yu.G., and Kulesh, V.F., Presnovodnye krevetki (Freshwater Prawns), Moscow: Agropromizdat, 1988.

Khmeleva, N.N., Kulesh, V.F., Alekhnovich, A.V., and Guiguinyak, Yu.G., Ekologiya presnovodnykh krevetok (Ecology of Freshwater Prawns), Minsk: Belaruskaya Navuka, 1997.

Kulesh, V.F., Growth and Survival Rate of the Giant Freshwater Prawn Macrobrachium rosenbergii (De Man) Depending on Stocking Density under Different Rearing Conditions, Gidrobiol. Zh., 1996, vol. 32, no. 4, pp. 10-16.

Kulesh, V.F., Prospects for Pond Polyculture of Freshwater Prawns Macrobrachium nipponense (De Haan) and Fish in Spillwater from a Thermal Power Plant in the Temperate 
Zone, Tez. dokl. VII Vserossiiskoi konf. po promyslovym bespozvonochnym (pamyati B.G. Ivanova) (Prod. VII AllRussia Conf. on Commercial Shellfishery in Memory of B.G. Ivanov), Moscow, 2006, pp. 289-291.

Kulesh, V.F. and Guiguinyak, Y.G., Development and Growth Heterogeneity in Oriental River Prawn, Macrobrachium nipponense (De Haan) (Palaemonidae), in Ontogenesis, Aquacult. Fish. Manag., 1993, vol. 24, pp. 751-760. Kuris, A.M., Ra'anan, Z., Sagi, A., and Cohen, D., Morphotypic Differentiation of Male Malaysian Giant Prawns, Macrobrachium rosenbergii, J. Crustac. Biol., 1987, vol. 7, pp. 219-237.

Lan, L.M., Long, D.N., and Micha, J., The Effects of Densities and Feed Types on the Production of Macrobrachium rosenbergii (De Man) in the Rotational Rice-Prawn System, Aquacult. Res., 2006, vol. 37, pp. 1297-1304.

Lan, L.M., Micha, J.C., Long, D.N., and Yen, P.T., Effect of Density and Culture System on Growth, Survival, Yield, and Economic Return of Freshwater Prawn, Macrobrachium rosenbergii, Farming in the Rice Field in the Mekong Delta, Vietnam, J. Appl. Aquacult., 2006, vol. 18, pp. 43-62. Malecha, S.R., Masuno, S., and Onizuka, D., The Feasibility of Measuring the Heritability of Growth Pattern Variation in Juvenile Freshwater Prawns, Macrobrachium rosenbergii (De Man), Aquaculture, 1984, vol. 38, pp. 347-363.
Mohanakumaran, N.C., Salin, K.R., Rajn, M.S., and Mothew, S., Economic Analysis of Monosex Culture of Giant Freshwater Prawn (Macrobrachium rosenbergii De Man): A. Case Study, Aquacult. Res., 2006, vol. 37, pp.949954.

New, M.B., Farming Freshwater Prawns: A Manual for the Culture of the Giant River Prawn (Macrobrachium rosenbergii), FAO Fisheries Technical Paper no. 428, Rome, Italy: FAO, 2002.

New, M.B., Freshwater Prawn Farming: Global Status, Recent Research and a Glance at the Future, Aquacult. Res., 2005, vol. 16, pp. 210-230.

Ra'anan, Z. and Cohen, D., The Effect of Group Interaction on the Development of Size Distribution in Macrobrachium rosenbergii (De Man) Juvenile Populations, Biol. Bull., 1984, vol. 166, pp. 22-31.

Ra'anan, Z. and Sagi, A., Alternative Mating Strategies in Male Morphotypes of the Freshwater Prawn Macrobrachium rosenbergii (De Man), Biol. Bull., 1985, vol. 169, pp. 592-601.

Sagi, A., Ra'anan, Z., Cohen, D., and Wax, Y., Production of Macrobrachium rosenbergii in Monosex Populations: Yield Characteristics under Intensive Monoculture Conditions in Cages, Aquaculture, 1986, vol. 51, pp. 265-275. 